\title{
Correlations of fibrosis in endomyocardial biopsies from patients with aortic valve disease
}

\author{
P J OLDERSHAW, I A B BROOKSBY, M J DAVIES, D J COLTART, \\ B S JENKINS, M M WEBB-PEPLOE \\ From the Cardiac Department, St. Thomas' Hospital, and the Department of Histopathology, \\ St. George's Hospital Medical School, London
}

SUMMARY The amount of fibrosis in endomyocardial biopsies from 55 patients with aortic stenosis and 42 patients with aortic regurgitation was measured. Sixty per cent of the patients with aortic stenosis had some degree of fibrosis; the degree of fibrosis correlated strongly with ejection fraction, peak systolic gradient, symptoms of cardiac failure, and mortality. In patients with aortic regurgitation, fibrosis was found in $\mathbf{4 0}$ per cent and was never severe. A correlation was found with symptoms of cardiac failure and mortality at follow-up, but not with ejection fraction or degree of regurgitation.

Endomyocardial biopsy is used mainly to establish a pathological diagnosis in myocardial disease. Characteristic histological changes are seen in infiltrative disorders such as amyloidosis, sarcoidosis, and haemochromatosis but such cases are rare. In the majority of cases of acquired heart disease and of cardiomyopathy, microscopy of the diseased ventricle shows only non-specific changes such as fibrosis, increase in fibre size, vacuolation of muscle fibres, abnormal arrangement of muscle fibres, inflammatory cell infiltration, and alteration of cell organelles. ${ }^{12}$ In this study, we set out to establish whether information obtained from the biopsy might predict patient prognosis.

The degree of fibrosis in endomyocardial biopsies from 97 patients with aortic valve disease was assessed. This was correlated with symptoms and the need for subsequent treatment of cardiac failure.

\section{Methods}

In this study, we included all patients who underwent cardiac catheterisation at St. Thomas' Hospital for aortic valve disease between 1973 and 1977. All gave informed consent for left ventricular biopsy. Each patient had right and left heart catheterisation including left ventricular angiography and coronary arteriography. Biopsies were taken with the modified Olympus fibreoptic bronchoscopic biopsy forceps ${ }^{3}$ which was introduced using the St. Thomas' long sheath technique. ${ }^{4}$ Specimens were taken from the left ventricle via Received for publication 16 June 1980 the sheath passed either retrogradely across the aortic valve or transseptally across the mitral valve. Where possible, the sheath was positioned so that specimens were taken from the free wall of the left ventricle towards the apex. (Three or four specimens were taken from the ventricle in each case.) The specimens were fixed immediately in 10 per cent formol-saline solution, processed, and cut by conventional methods. Sections, $6 \mu$ thick, were stained with haematoxylin and eosin and a modified trichrome, elastic van Gieson. The proportion of collagen was obtained in sections stained by the trichrome method, by means of a standard pointcounting technique with a 25 point graticule in the eyepiece of the microscope. All specimens were analysed by a pathologist who was unaware of details of the patient's diagnosis.

The degree of fibrosis of the ventricle in each patient was compared with: (1) age of the patient; (2) the presence of hypertension before catheterisation (systolic blood pressure $\geqslant 140 \mathrm{mmHg}$ ), (3) electrocardiographic evidence of left ventricular hypertrophy (V1 S + V6 R $\geqslant 35 \mathrm{~mm}$ ); (4) coronary arteriographic evidence of ischaemic heart disease (stenosis $\geqslant 70 \%$ of normal vessel diameter); (5) ejection fraction as measured at cardiac catheterisation; (6) peak systolic gradient across the aortic valve or degree of aortic regurgitation; (7) the patient's symptoms and requirements for antifailure therapy.

All results are given as the mean \pm the standard error of the mean. Differences between groups were assessed using Student's t test. 


\section{Results}

\section{(a) PATIENTS}

Left ventricular endomyocardial biopsies were obtained from 97 patients with aortic valve disease. In 55 of these patients ( 30 men, 25 women) aortic stenosis was the dominant lesion; in 42 (34 men, 8 women) aortic regurgitation was dominant. The mean age of patients with aortic stenosis was 59 years (range 30 to 72 years), and of those with aortic regurgitation 48 years (range 22 to 67 years). There was no correlation between degree of fibrosis and patient age or with duration of symptoms. Fortytwo of the patients with aortic stenosis, and 25 of the patients with aortic regurgitation required aortic valve replacement.

Table 1 Relation of percentage fibrosis to peak systolic gradient and ejection fraction (both measured at cardiac catheterisation) in patients with aortic stenosis

\begin{tabular}{|c|c|c|c|c|c|}
\hline \multirow{2}{*}{$\begin{array}{l}\text { Per } \\
\text { cent } \\
\text { fibrosis }\end{array}$} & \multirow[t]{2}{*}{$\begin{array}{l}\text { No. of } \\
\text { patients }\end{array}$} & \multirow{2}{*}{$\begin{array}{l}\text { Mean peak } \\
\text { systolic } \\
\text { gradient } \\
( \pm S E M)\end{array}$} & \multicolumn{3}{|c|}{$\begin{array}{l}\text { No. of patients with ejection } \\
\text { fraction }\end{array}$} \\
\hline & & & $>0.55$ & $0.30-0.55$ & $<0.30$ \\
\hline $\begin{array}{l}0 \\
0-5 \\
5-10 \\
10-15 \\
15-20 \\
20-30\end{array}$ & $\begin{array}{r}22 \\
20 \\
6 \\
4 \\
1 \\
2\end{array}$ & $\begin{array}{l}67 \pm 9 \\
82 \pm 10 \\
82 \pm 12 \\
86 \pm 16 \\
88 \\
95\end{array}$ & $\begin{array}{r}15 \\
8 \\
3 \\
1 \\
-\end{array}$ & $\begin{array}{r}7 \\
11 \\
2 \\
1 \\
1 \\
-\end{array}$ & $\begin{array}{l}-1 \\
1 \\
\frac{2}{2}\end{array}$ \\
\hline
\end{tabular}

\section{(b) AORTIC STENOSIS}

Thirty-three $(60 \%)$ of the 55 patients had fibrosis in the myocardial biopsy. The percentage fibrosis in these patients showed no significant correlation with pre-existing hypertension, electrocardiographic evidence of left ventricular hypertrophy, or coexisting ischaemic heart disease. There was, however, a significant correlation $(r=0.78, p<0.02)$ with the left ventricular ejection fraction. The mean ejection fraction of patients with fibrosis was 0.43 as compared with 0.56 for patients without fibrosis $(p<0.01)$ (Table 1). Similarly, a significant correlation was found with the peak systolic gradient across the aortic valve as measured at cardiac catheterisation. Patients with fibrosis had a mean peak systolic gradient of $83 \mathrm{mmHg}$ which was significantly greater than that for patients without fibrosis$67 \mathrm{mmHg}(\mathrm{p}<0.01)$.

The percentage of fibrous tissue also correlated strongly with symptoms, the need for antifailure treatment, and mortality (Table 2). Of the 33 patients with fibrosis, 16 required antifailure
Table 2 Relation of percentage fibrosis to requirement for aortic valve replacement and medical antifailure treatment at follow-up in patients with aortic stenosis

\begin{tabular}{|c|c|c|c|c|c|}
\hline \multirow{2}{*}{$\begin{array}{l}\text { Per } \\
\text { cent } \\
\text { fibrosis }\end{array}$} & \multirow{2}{*}{$\begin{array}{l}\text { No. of } \\
\text { patients }\end{array}$} & \multirow{2}{*}{$\begin{array}{l}\text { No. of patients } \\
\text { requiring aortic } \\
\text { valve } \\
\text { replacement }\end{array}$} & \multicolumn{3}{|c|}{ Follow-up treatment requirements } \\
\hline & & & $\begin{array}{l}\text { No } \\
\text { treatment }\end{array}$ & Treatment & Dead \\
\hline 0 & 22 & 15 & $19(12)^{\star}$ & $3(3)$ & - \\
\hline $0-5$ & 20 & 16 & $6(5)$ & $10(8)$ & $4(3)$ \\
\hline $5-10$ & 6 & 5 & 1 (1) & $2(2)$ & $3(2)$ \\
\hline $10-15$ & 4 & 3 & - & $3(2)$ & $1(1)$ \\
\hline 15-20 & 1 & 1 & - & $1(1)$ & - \\
\hline $20-30$ & 2 & 2 & 一 & - & $2(2)$ \\
\hline
\end{tabular}

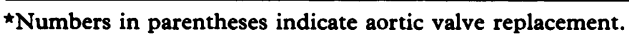

therapy and 10 died during the follow-up period of this study; of the 22 patients without fibrosis only three required treatment and there were no deaths. Of the 10 patients with dominant stenosis who died, two died suddenly while waiting for surgery, two died during cardiac bypass, three died in the immediate postoperative period (one died with septicaemia, two died with presumed arrhythmia), and three died after discharge having had aortic valve surgery (one with increasing left ventricular failure, two undiagnosed).

Twenty-seven $(82 \%)$ of the 33 patients with fibrosis and $15(68 \%)$ of the 22 patients without fibrosis had aortic valve replacement.

\section{(c) AORTIC REGURGITATION}

Fibrosis was found in $17(40 \%)$ of the 42 patients; the percentage fibrosis, with the exception of one case, was less than 5 per cent. There was no correlation in these patients between percentage fibrosis and pre-existing hypertension, electrocardiographic evidence of left ventricular hypertrophy, or ischaemic heart disease nor with left ventricular ejection fraction or the degree of regurgitation. Percentage fibrosis was related to follow-up symptomatology and requirement for

Table 3 Relation of percentage fibrosis to requirement for aortic valve replacement and to symptomatology at follow-up in patients with aortic regurgitation

\begin{tabular}{llllll}
\hline $\begin{array}{l}\text { Per } \\
\text { cent } \begin{array}{l}\text { No. of } \\
\text { patients }\end{array}\end{array}$ & $\begin{array}{l}\text { No. of patients } \\
\text { requiring aortic } \\
\text { valve } \\
\text { replacement }\end{array}$ & \begin{tabular}{l} 
Follow-up treatment requirements \\
\cline { 5 - 6 }
\end{tabular} & $\begin{array}{l}\text { No } \\
\text { treatment }\end{array}$ & Treatment & Dead \\
\hline 0 & 25 & 15 & $22(13) \star$ & $1(1)$ & $2(1)$ \\
$0-5$ & 16 & 9 & $10(5)$ & $4(3)$ & $2(1)$ \\
$5-10$ & - & - & - & - & - \\
$10-15$ & 1 & 1 & - & $1(1)$ & -
\end{tabular}

^Numbers in parentheses indicate aortic valve replacement. 
antifailure therapy (Table 3). In the absence of fibrosis, only one of 23 patients required antifailure treatment at follow-up, whereas five of 15 patients with fibrosis required such treatment. Of the $\mathbf{4 2}$ patients studied, four died in the follow-up period. Two of these had no fibrosis, two had less than 5 per cent fibrosis; two of these deaths followed cardiac arrests while the patients were awaiting aortic valve surgery, and two occurred several years after operation because of increasing left ventricular failure.

Ten (59\%) of the 17 patients with fibrosis and 15 $(62 \%)$ of the 24 patients without fibrosis had aortic valve replacement.

\section{Discussion}

To date, endomyocardial biopsy has been largely used to establish a pathological diagnosis and little work has been performed in trying to correlate histology with clinical findings. Two notable exceptions to this are found in the work of Kuhn et $a l .^{5}$ and Kunkel et $a l .,^{6}$ both of whom studied congestive cardiomyopathy. Kuhn et al..$^{5}$ concluded that endomyocardial biopsy allowed clear prognostic separation in patients with congestive cardiomyopathy, and was of diagnostic value in patients with mild cardiomegaly and a short history of symptoms. Kunkel et al. ${ }^{6}$ also found good agreement in congestive cardiomyopathy between clinical and morphological changes. In this study, we have compared biopsy findings in patients with aortic valve disease with clinical symptomatology and mortality. Patients with aortic valve disease were used because their exercise tolerance remains poor after aortic valve replacement when left ventricular function is impaired preoperatively. ${ }^{7}$ We measured the percentage of fibrosis in left ventricular biopsies from such patients to see if this was a contributory factor towards this effect.

In patients with dominant aortic stenosis, the degree of fibrosis showed good correlation with left ventricular function as assessed by the left ventricular ejection fraction at cardiac catheterisation, and also with the severity of the stenosis as measured by the peak systolic gradient across the aortic valve. The amount of fibrosis also proved useful in the prediction of prognosis, and correlated well with symptoms at follow-up, with requirements for antifailure therapy, and with mortality.

Patients with dominant aortic regurgitation developed fibrosis less frequently and to a less severe degree than patients with dominant stenosis. It was therefore difficult to relate fibrosis to left ventricular function or degree of regurgitation. The relation between percentage fibrosis and patient prognosis, however, still held.

In patients with either dominant aortic stenosis or regurgitation, there was no correlation with age, duration of symptoms, hypertension, electrocardiographic evidence of left ventricular hypertrophy, or coronary artery disease.

We suggest that the role of endomyocardial biopsy is not yet fully realised, and in the future this technique may be useful beyond simply establishing a pathological diagnosis.

\section{References}

1 Olsen EGJ. Diagnostic value of the endomyocardial bioptome. Lancet 1974; i: 658-60.

2 Brooksby IAB, Jenkins BS, Coltart DJ, Webb-Peploe MM, Davies MJ. Left ventricular endomyocardial biopsy. Lancet 1974; ii: 1222-5.

3 Richardson PJ. King's endomyocardial bioptome. Lancet 1974; i: 660-1.

4 Brooksby IAB, Swanton RH, Jenkins BS, WebbPeploe MM. Long sheath technique for introduction of catheter tip manometer or endomyocardial bioptome into left or right heart. Br Heart $\mathcal{F}$ 1974; 36: 908-12.

5 Kuhn H, Knieriem HJ, Lösse B, et al. Prognosis and possible presymptomatic manifestations of congestive cardiomyopathy (COCM). Postgrad Med f 1978; 54: 451-9.

6 Kunkel B, Lapp H, Kober G, Kaltenbach M. Correlations between clinical and microscopic findings and natural history in congestive cardiomyopathy. In: Kaltenbach M, Loogen F, Olsen EGJ. eds. Cardiomyopathy and myocardial biopsy. Berlin: Springer, 1978: 271-83.

7 Brooksby IAB, Jenkins BS, Coltart DJ, Williams BT, Braimbridge MV, Webb-Peploe MM. Aortic valve replacement: the influence of ventricular function on the immediate and long term outcome. Eur Cong Cardiol.

Requests for reprints to Dr P J Oldershaw, Brompton Hospital, Fulham Road, London SW3 6HP. 